\title{
DEVELOPMENT OF THE NEW EDUCATIONAL CONTENT "SMALL UAS IN CIVIL ENGINEERING APPLICATION SCENARIOS"
}

\author{
E. Levin ${ }^{\mathrm{a}}$, K. Vach ${ }^{\mathrm{b}}$, R. Shults ${ }^{\mathrm{c}}$ \\ ${ }^{a}$ Michigan Technological University School of Technology, Townsend Drive, 1400, Houghton, Ml 49931- 1295, USA, \\ elevin@mtu.edu \\ ${ }^{b}$ EuroGV s.r.o. - geodetic and photogrammetric surveys, Opletalova 1284/37, 11000 Praha 1 - Nové Město, Czech Republic, \\ vach@eurogv.cz \\ ${ }^{\mathrm{c}}$ Kyiv National University of Construction and Architecture, Faculty for Geoinformation Systems and Territory Management, \\ Povitroflotskyi Avenue, 31 Kyiv, 03037, Ukraine, shults@gmail.com
}

Commission V, WG V/7

KEY WORDS: architecture, civil engineering, 3D modelling, applied photogrammetry, unmanned aerial system

\begin{abstract}
The key point of this paper is presentation of the main idea and some results of the project "Small UAS in civil engineering application scenarios" (SUAS-CAS). This project was proposed by newly established in 2016 ISPRS WG V/7: "Innovative Technologies in Training Civil Engineers and Architects". Here we are presenting our experience in using low-cost UAS in training architects at Kyiv National University of Construction and Architecture, which was chosen as basic for this project. In the first part of paper, the project outline is presented. Then the first and possible follow project outcomes were described. In some details is described the training module "Small UAS in architecture" which was developed and included as a part of the subject "Architectural photogrammetry".
\end{abstract}

\section{INTRODUCTION}

The modern world creates its own demands. In the context of the incredible mobility of people on the planet and the absolute availability of communications in all parts of the globe, the educational process cannot be kept away from these global processes. Today students have a wide range of possibilities to get an education in most universities in the world. The only restrictions might be financial conditions and varieties of cultural and religious principles of society (Kravchenko, Luhmann et al., 2016). The necessary conditions for education in other countries are knowledge of modern computer and communication technologies and a high level of foreign language skills (mostly English). With the required level of training in communication, language and cultural environment and financial support through grants, government programs and sponsorship student can establish wider educational projects and achieve desired goals in education.

In today's world, decision support in multiple civil engineering application scenarios is widely supported by geospatial information. Challenge in training of modern civil engineers and architects is to provide them with balanced education and training in geospatial science and technology to prepare them for collection and processing of that data. To meet this challenge, newly established in 2016 ISPRS WG V/7: "Innovative Technologies in Training Civil Engineers and Architects" proposed to design computer and UAV aided teaching and learning module exploring geospatial application scenarios of decision support in verification of the state and "health" of various civil infrastructure objects such as buildings, bridges, road/railroad pavements and others.

\section{PROJECT OUTLINE}

Specifically proposed project comprises: a) practical experience in small UAS (SUAS) imagery acquisition at in-room and outside environments; b) review and comparative analysis of the classical photogrammetry and computer vision based methods of the UAS data processing; c) commercial and open-source software review; d) accuracy considerations and compatibility with application requirements analysis. Educational outcomes of the proposed project encompass: 1) understanding of small UAV flight planning and limitations of the SUAS platforms and sensors; 2) knowledge of contemporary issues in sensor modeling and calibration deploying classical photogrammetric methods versus computer vision; 3) understanding of technological steps for 3D modeling and geospatial analytics of commercial-of-the-shelf and open-source software packages; 4) hands-on expertize of SUAS data acquisition and processing; 5) understanding of legal regulations of SUAS deployment in airspace of the different countries; 6) profound understanding of SUAS sensors platforms and methods matching to accuracy and procedural needs of the civil engineering application scenarios.

In order to achieve these aims, ISPRS WG V/7 proposed to develop educational content "Small UAS in Civil Engineering Application Scenarios" (SUAS-CAS). SUAS-CA is aimed in development of the unique computer based educational materials that will optimally integrate education in fundamental problems associated with geospatial data obtaining and processing in civil engineering applications with training in SUAS systems use in response to that kind of applications.

The following objectives are established for the proposed SUAS-CAS project:

$\rightarrow \quad$ Objective-1: Development of the multimedia training content covering topics associated with SUAS use in civil engineering and architecture application scenarios.

$\rightarrow \quad$ Objective-2: Creation of the practical lab content based on in-room and outside data acquisition.

$\rightarrow \quad$ Objective 3: Establishing the outreach and data dissemination strategy for SUAS-CAS use for ISPRS 3S seminars and integration to UN university programs. 
Due to commonly accepted research and development projects methodology SUAS-CAS objectives will be realized towards following project tasks:

$\rightarrow \quad$ Task-1: Analytical review and selection of rotary and fixed wing SUAS platforms suitable for the project.

$\rightarrow \quad$ Task-2: Analytical review and selection of commercial-off-the-shelf and open source software systems.

$\rightarrow \quad$ Task-3: Preparation of the SUAS-CAS syllabus.

$\rightarrow \quad$ Task-4: Preparation and multimedia recording of the SUAS-CAS lectures.

$\rightarrow \quad$ Task-5: Establishing of SUAS-CAS hands-on components.

$\rightarrow \quad$ Task-6: Develop SUAS-CAS web-portal.

$\rightarrow \quad$ Task-7: SUAS-CAS approbation at ISPRS Kyiv workshop.

$\rightarrow \quad$ Task-8: Create SUAS-CAS outreach and data dissemination strategy.

SUAS-CAS project will be culminated in establishing and approbation of the educational modules, which will include online training manual on the collection and processing of UAV geospatial data, educational website available for training and education of civil engineers and architects worldwide. Fig. 1 depicts schematically operational structure of the proposed SUAS-CAS project after successful completion.

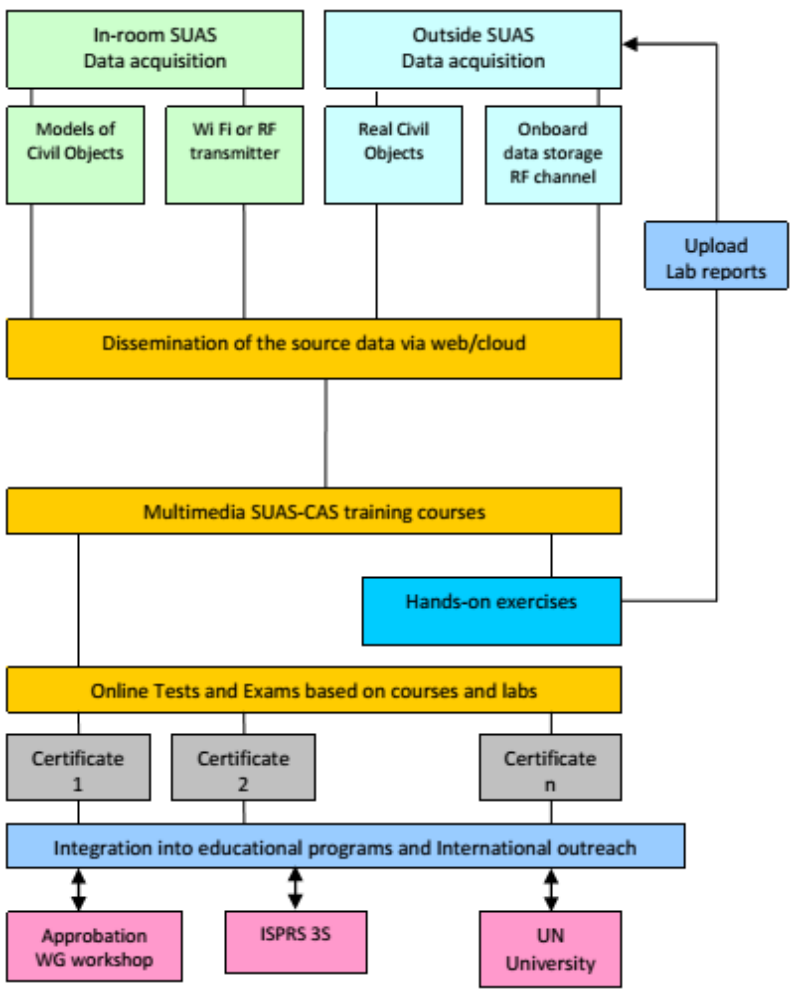

Figure 1. The SUAS-CAS educational content (operational structure)

Support by proposed project implementation strategy of use simultaneously of in-room and outside platforms will make it possible to delivery educational courses even in those parts of the world, which have some legal constraints for flying SUAS in their airspace. Kyiv National University of Construction and Architecture is equipped with multiple in-room models to support in-room project approbation. Our decision to select that school for SUAS approbation was not spontaneous. Ukraine, as a young European state passed a difficult stage of its democracy development. The transition from outdated concepts and technologies of the XX century to modern technologies of XXI century is not always goes without errors. One of the reason for this situation is the low skills level in holding of the latest world achievements in the field of science and technology. This in turn is due to the absence or weak deployment of modern technology in the educational process and the promotion of new developments. Among these technologies is certainly true technology of collecting geospatial data using UAVs.

SUAS-CAS will be implemented as a summary of the following project efforts: 1) identification and acquisition of the in-room and outside SUAV platforms (rotary or fixed wing); 2) analytical review of the commercial-of-the-shelf and open source software systems suitable for the SUAS data processing; 3) preparation of lectures and recording then in multimedia formats; 4) work on quizzes and SUAS-CAS final test; 5) development of in-room and outside practical labs. Use of inroom nano-UAVs may be helpful to resolve a problem of getting SUAS data when flying of the outside platforms will not be available due to weather or legal factors at specific locations.

\section{PROJECT OUTCOMES}

Solution of presented previously tasks will lead to many goodies. The following project outcomes are expected and will be shared with ISPRS members:

A) Learning outcomes:

$\rightarrow \quad$ understanding of small UAV flight planning and limitations of the SUAS platforms and sensors;

$\rightarrow \quad$ knowledge of contemporary issues in sensor modelling and calibration deploying classical photogrammetric methods versus computer vision;

$\rightarrow \quad$ understanding of technological steps for 3D modelling and geospatial analytics of commercial-of-the-shelf and opensource software packages;

$\rightarrow \quad$ hands-on expertize of SUAS data acquisition and processing;

$\rightarrow \quad$ understanding of legal regulations of SUAS deployment in airspace of the different countries;

$\rightarrow \quad$ profound understanding of SUAS sensors platforms and methods matching to accuracy and procedural needs of the civil engineering application scenarios.

B) Research outcomes:

$\rightarrow \quad$ SUAS-CAS is establishing web-site that may be used by UAV photogrammetry researchers to exchange ideas and data on UAV data processing;

$\rightarrow \quad$ project orientation to open-sourced software systems makes it possible SUAS-CAS to become a research algorithms exchange framework since that open-source systems can be feasibly amended by functions created by developer community;

$\rightarrow \quad$ civil engineering researchers may expand a list of traditional SUAS supported application scenarios by bringing new ones for discussion by SUAS-CAS users group.

C) Societal/outreach outcomes:

$\rightarrow \quad$ SUAS-CAS is based on inexpensive platforms and systems and then can be deployed by students and specialists of developing countries including crowdsourcing data obtaining scenarios;

$\rightarrow \quad$ data and SUAS-CAS content dissemination strategy makes it possible to use in many ISPRS and national geospatial societies activities such as ISPRS $3 \mathrm{~S}$ seminars and UN university component; 
$\rightarrow \quad$ project first approbation in Ukraine 1) will help ordinary non-professional user's fields (environmentalists, firefighters, police officers, archaeologists, journalists, etc.) in Ukraine to integrate confidently low-cost UAV technology into their operations; and 2) will help to create optimal conditions for education of schoolboys and students of use UAV technology to solve non-standard problems in their future careers. SUAS-CAS can be accommodated by undergraduate, graduate and continuous education programs.

All proposed project educational components will be integrated on SUAS-CAS web-site. Concentration on low cost SUAS platforms and open source software systems makes SUAS-CAS to be a viable candidate for the deployment by educators and engineers of developing countries at the different parts of the world. Tentative auditory for the content delivery will graduate, post-graduate students and professionals from industry that will be interested to enroll in SUAS-CAS.

\section{FIRST RESULTS}

The first step of this project was carried out in Kyiv national university of construction and architecture. The main purpose at this stage was development of a small educational module for architects. The educational module presented below consists from the follow chapters:

1. Short review of state-of-the-art small UAS and freeware or low-cost photogrammetric software.

2. Creation of small UASs surveying project with using specialised software, choosing of small UAS model and camera parameters.

3. Small UASs camera calibration.

4. Small UASs data post-processing.

5. Results export to specialised software for construction modelling.

In order to achieve this aim were used architectural in-room models. Some of examples of such models are presented in Fig. $2-4$.

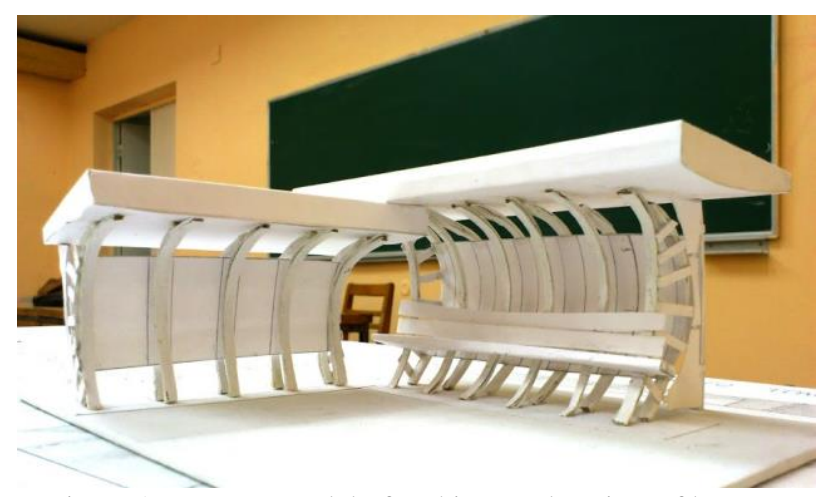

Figure 2. In-room model of architectural project of bus stop (variant 1)

Students created all of these models. It is a typical task for students who are training at architectural faculty. In such way they are trying to realise own ideas. However, during creation these in-room models students do not account the properties of construction materials and main laws of structural mechanic. That is why they need 3D models of their in-room models in order to check whether their projects will durable, stiff and reliable or not. This is the main reason why small UAS data suitable for 3D model creation in this particular case.

In order to sort out this task, first of all we introduced a short overview about current state of UAS technologies and freeware photogrammetric software. It allowed students to chose correct UAS model, camera and software.

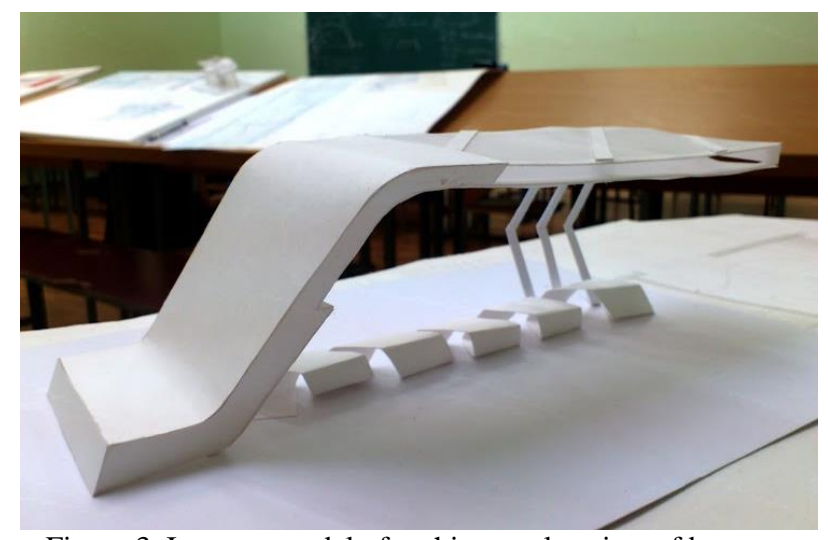

Figure 3. In-room model of architectural project of bus stop (variant 2)

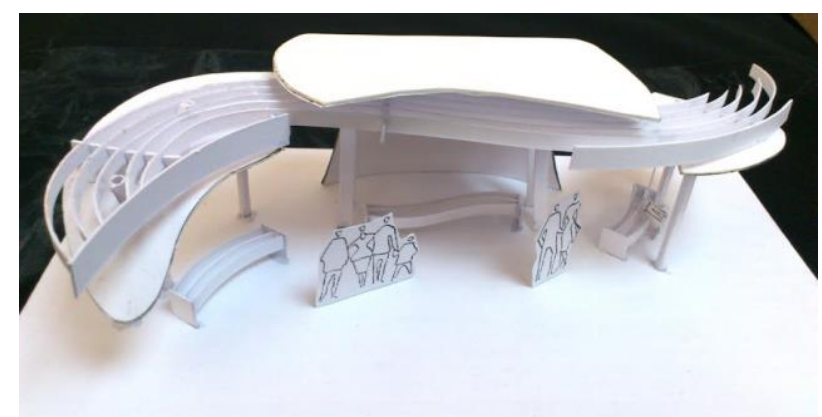

Figure 4. In-room model of architectural project of bus stop (variant 3)

The approximate size of models equals $30 \times 15 \times 15 \mathrm{~cm}$ and therefore the model scale equal 1:20.

In our case, for data collection three models of UAS (Shults, 2017) were chosen (Fig. 5-7). As software for data processing, AgiSoft PhotoScan was chosen.

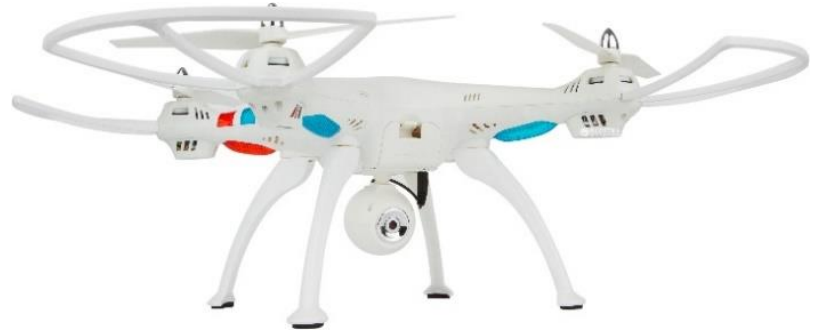

Figure 5. Small UAS Kingco K88W

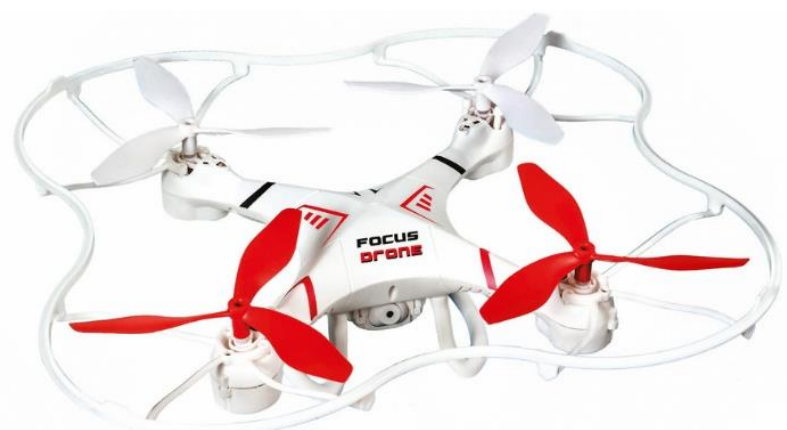

Figure 6. Small UAS Focus drone 


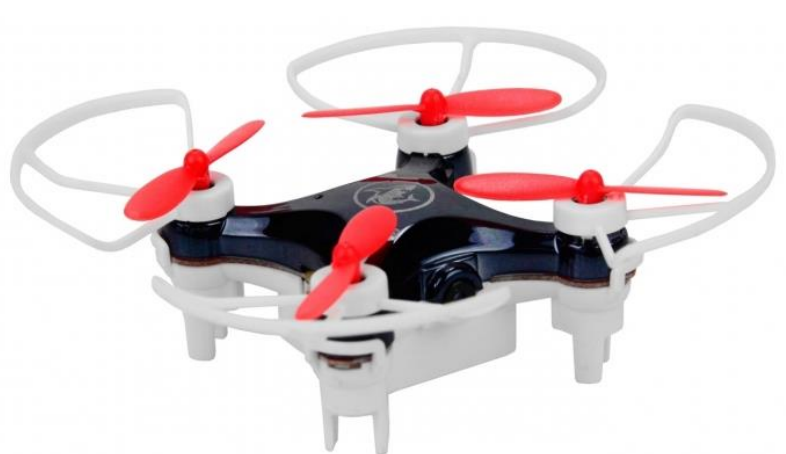

Figure 7. Nano UAS Focus drone

After lecture about main principles of the camera calibration, was done calibration for all three cameras. The camera calibration was done with using Agisoft Lens calibration software. This software was chosen according to results of our previous researches (Shults et al., 2017). One of results of camera calibration for nano UAS is presented in Fig. 8.

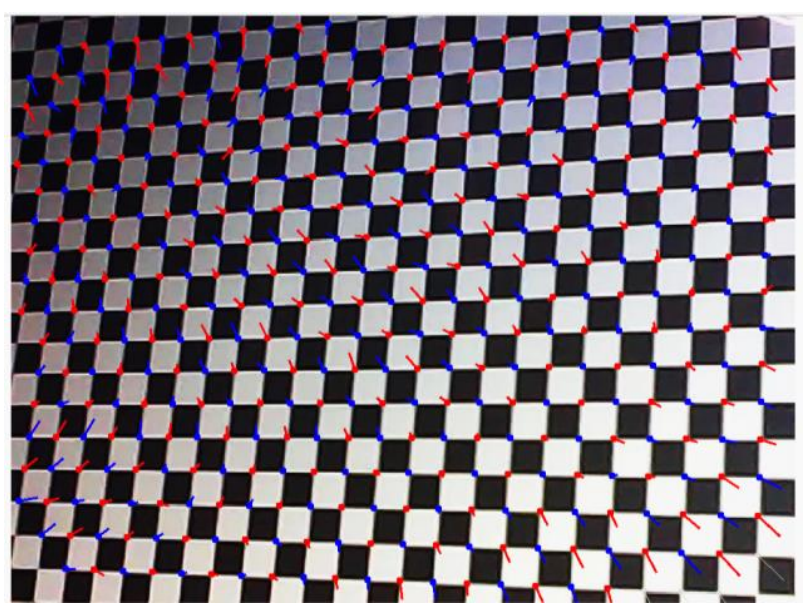

Figure 8. Distortion field of nano UAS Focus drone

As we can see, the distortion field has not only extreme values of radial component but also huge meanings of affinity distortion. The camera calibration parameters presented in Fig. 9 below.

\begin{tabular}{|lll}
\hline Parameter & Value & Std Error \\
Image width & 1280 & \\
Image height & 960 & \\
Focal length & 2830.04 & 3.59673 \\
Principal point (x) & -84.7114 & 1.43983 \\
Principal point (y) & 59.9087 & 2.01401 \\
Affinity B1 & -168.12 & 0.548078 \\
Skew B2 & -0.253698 & 0.617455 \\
Radial K1 & 0.102128 & 0.00925112 \\
Radial K2 & -0.608961 & 0.103884
\end{tabular}

Figure 9. Calibration results of nano UAS Focus drone

The accuracy of calibration allows to carry out images postprocessing and 3D modelling. Totally, for each in-room model more than 25 images were got. The surveying scheme in each case was similar. The surveying had been carrying out in plane for circular trajectory.

In order to improve orientation process 12-bit coded targets were used.

After images orientation and model scaling the 3D modelling of constructions was done. For instance in Fig. 10 presented the results of constructions $3 \mathrm{D}$ modeling.

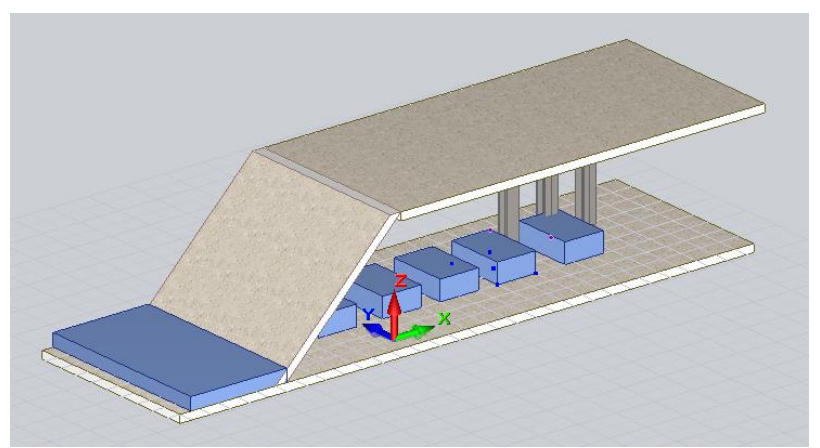

Figure 10. 3D model of architectural project of bus stop (variant 2)

On the following step, this 3D model was exported in one of well-known CAD file format. In our case it was *.dxf. This CAD model was uploaded in special software for structural engineering analysis and design (LIRA-SAPR, 2017). This software allows to carry out constructions analysis by using finite element method. The finite element model of architectural project presented in Fig. 11.

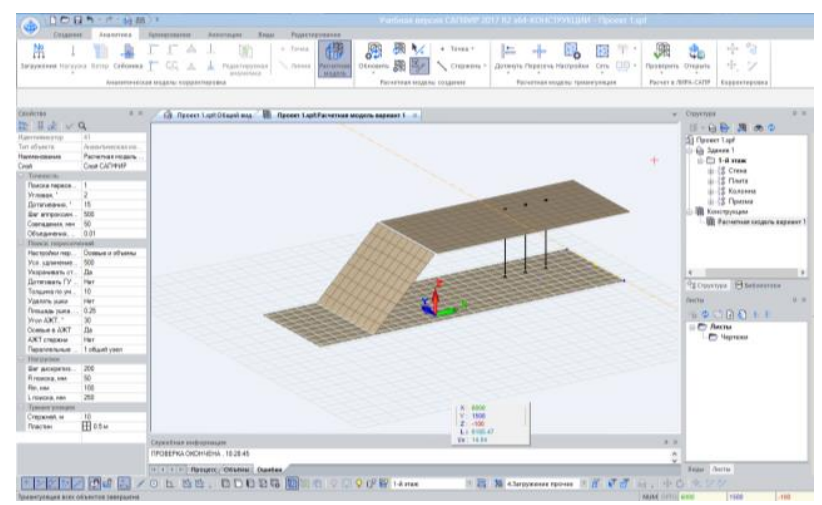

Figure 11. Finite element model of architectural project of bus stop (variant 2)

Using the results of structural engineering analysis students assessed their projects and make appropriate corrections in order to improve design results. At the same time, the analysis results brought them new ideas and emphasized necessity of combination of different design technologies.

\section{CONCLUSIONS}

In this paper, the first attempt of project description "Development of the new educational content "Small UAS in civil engineering application scenarios" was made. Educational module for architects was developed and described. This module was implemented as a part of course "Architectural photogrammetry" for the second year students at Kyiv National University of Construction and Architecture. During the lessons students carried out step-by-step all necessary operations in order to transform their own in-room models in to 3D digital form. These 3D models were used for analysis in software for constructions modelling. For instance finite element model analysis for each 3D model was done. It allowed to improve buildings reliability and durability. From the other hand, such approach allows students to understand better the whole process of buildings design.

All results will be used at the following step of our project, which contains of creation of educational on-line resource devoted to using small UAS in civil engineering and architecture applications. 


\section{ACKNOWLEDGEMENTS}

We gratefully acknowledge for the promotion and financial support of the International Society for Photogrammetry and Remote Sensing (ISPRS). Thanks to ISPRS financial support, Kyiv National University of Construction and Architecture got an opportunity to implement modern photogrammetric technologies in educational process.

\section{REFERENCES}

LIRA-SAPR, 2017 Structural Engineering Analysis \& Design Software, Version 2017 R3. https://www.liraland.com.

Shults, R., 2017. Simulation of Inertial Navigation System Errors at Aerial Photography from UAV, ISPRS Int. Arch. Photogramm. Remote Sens. Spatial Inf. Sci., XLII-1-W1, 2017, pp. 345-351.

Shults, R., Krelshtein, P., Kravchenko, I., Rogoza, O., Kyselov, O., 2017. Low-Cost Photogrammetry for Culture Heritage, 10th International Conference "Environmental Engineering", Lithuania.

Kravchenko, I., Luhmann, T, Shults, R., 2016 Concept and Practice of Teaching Technical University Students to Modern Technologies of 3D Data Acquisition and Processing: A Case Study of Close-Range Photogrammetry and Terrestrial Laser Scanning. ISPRS Int. Arch. Photogramm. Remote Sens. Spatial Inf. Sci., Volume XLI-B6, 2016 XXIII ISPRS Congress, 12-19 July 2016, Prague, Czech Republic. 